\section{Revista Brasileira de Administração Científica}

Brazilian Journal of Scientific Administration

Abr a Jun 2020 - v.11 - n.2

\title{
Criticidade dos estoques de uma empresa do agronegócio brasileiro simulada a partir de uma modelagem matemática
}

A logística vem exercendo um papel fundamental no processo de expansão das empresas, ao se tornar um fator determinante de competitividade para a gestão logística de estoque, ferramenta essa, de grande valia para as organizações que buscam uma melhor performance na sua gestão. A realização deste trabalho teve como objetivo a análise do grau de criticidade XYZ sob à luz dos resultados obtidos pela curva $A B C$ obtidos em uma empresa mineira do agronegócio. Através da pesquisa, utilizou-se de um estudo de caso com aplicação de revisão bibliográfica, análise de documentos e observação participante. As informações foram tratadas e corroboradas por meio de visita à empresa. A partir do estudo, pôde-se conhecer as políticas de gestão de estoques adotadas e perceber o interesse da empresa em dar continuidade a futuros projetos que envolvam as classificações XYZ e ABC, uma vez que a pesquisa trouxe reflexos diretamente na busca pela competitividade e inovação para a gestão de produtos no agronegócio Brasileiro. Por fim, como resultado do trabalho, foi detectado que a empresa reconhece a importância dos modelos de criticidade e classificação apresentados, ao confirmar que a proposta pode evitar perdas de produtos e proporcionar uma gestão mais eficiente no que tange à gestão de sua cadeia de suprimentos.

Palavras-chave: Logística; Estoque; Agronegócio.

\section{Criticity of the stocks of a Brazilian agribusiness company simulated from a mathematical modeling}

Logistics has been playing a fundamental role in the expansion process of companies, as it has become a determining factor of competitiveness for the logistics management of inventory, a tool that is of great value for organizations that seek a better performance in their management. The purpose of this work was to analyze the degree of criticality $X Y Z$ in the light of the results obtained by the ABC curve obtained in a mining company in agribusiness. Through the research, it was used a case study with application of bibliographic review, analysis of documents and participant observation. The information was treated and corroborated through a visit to the company. From the study, it was possible to learn about the inventory management policies adopted and realize the company's interest in continuing future projects involving the XYZ and $\mathrm{ABC}$ classifications, since the research directly reflected the search for competitiveness and innovation for product management in Brazilian agribusiness. Finally, as a result of the work, it was detected that the company recognizes the importance of the models of criticality and classification presented, by confirming that the proposal can avoid losses of products and provide a more efficient management regarding the management of its supply chain.

Keywords: Logistics; Stock; Agribusiness.

Topic: Planejamento, Estratégia e Competitividade

Reviewed anonymously in the process of blind peer.
Received: $19 / 03 / 2020$

Approved: 01/04/2020
Ludhyane de Carvalho Eleuthério

Instituto Federal do Sudeste de Minas Gerais, Brasil http://lattes.cnpq.br/6368298822524405

ludhyane.Ice@gmail.com

Vinicius Passos Nogueira (iD)

Instituto Federal do Sudeste de Minas Gerais, Brasil

http://lattes.cnpq.br/8470797400619277

http://orcid.org/0000-0003-1344-5888

viniciuspn@bol.com.br

Salvador Quintão Barbosa Junior (iD)

Instituto Federal do Sudeste de Minas Gerais, Brasil

http://lattes.cnpq.br/1112119065604199

http://orcid.org/0000-0003-2467-482X

barbosasalvador10@gmail.com

\author{
Helder Antônio da Silva (iD \\ Instituto Federal do Sudeste de Minas Gerais, Brasil \\ http://lattes.cnpq.br/2218608850099932 \\ http://orcid.org/0000-0002-7192-7052 \\ helder.silva@ifsudestemg.edu.br \\ José Carlos de Cnop Siqueira (it) \\ Instituto Federal do Sudeste de Minas Gerais, Brasil \\ http://lattes.cnpq.br/1159584348192563 \\ http://orcid.org/0000-0002-3321-9928 \\ josecarlos.decnop@ifsudestemg.edu.br
}

Referencing this:

ELEUTHÉRIO, L. C.; NOGUEIRA, V. P.; BARBOSA JUNIOR, S. Q.; SILVA, H. A.; SIQUEIRA, J. C. C.. Criticidade dos estoques de uma empresa do agronegócio brasileiro simulada a partir de uma modelagem matemática. Revista Brasileira de Administração Científica, v.11, n.2, p.98-106, 2020. DOI: http://doi.org/10.6008/CBPC2179-

DOI: 10.6008/CBPC2179-684X.2020.002.0007 $\underline{684 X .2020 .002 .0007}$ 


\section{INTRODUÇÃO}

No século XX, a produção em massa teria que lidar com eventuais incertezas do mercado, onde havia desvantagens em relação aos custos de armazenagem que serviam como amortecedores em relação à demanda dos consumidores e, nesta situação, as empresas buscavam as soluções através de uma política do gerenciamento logístico dos estoques (BOWERSOX et al., 2001).

Para Sucena (2012), o Conselho de Administração Logística (Council of Logistics Management), associação mundial sem fins lucrativos para aperfeiçoamento e desenvolvimento dos profissionais que lidam com logística e gestão de cadeias de suprimento, afirma que um eficiente gerenciamento logístico, além de ser um elemento integrador, funciona "como o processo de planejamento, implementação e controle do fluxo eficiente e economicamente eficaz de matérias-primas, [...] desde o ponto de origem até o ponto de consumo, com o propósito de atender às exigências dos clientes".

Para Pozo (2007), todas as organizações devem preocupar-se com modernas técnicas de gerenciamento dos estoques, pois quando bem empregadas, impactam de maneira significativa no resultado de toda a empresa. $\mathrm{O}$ autor ainda ressalta que um planejamento adequado com inovadores métodos permite diminuir custos e ampliar os investimentos que em toda cadeia de suprimentos.

A relevância do planejamento de estoques quando bem planejados, são capazes de minimizar os custos da manutenção dos materiais no almoxarifado, ao realizar uma análise criteriosa de quanto investir, quando o pedido deverá ser realizado e, sobretudo, a forma com que esses estoques deverão ser controlados (LOPES et al., 2008).

A partir deste pressuposto, a presente pesquisa ancorou, como objetivo central, em realizar a classificação $X Y Z$ a partir dos dados encontrados na curva $A B C$ de uma empresa do agronegócio situada na zona da mata mineira, sob duas óticas dispostas, a seguir: I - analisar o gerenciamento da distribuição física dos produtos em estoque e II - discutir a classificação de criticidade XYZ a partir dos resultados obtidos pela curva $A B C$.

Em um segundo instante, comparou-se os resultados com o proposto por Babai et al. (2015) ao afirmarem que a classificação de criticidade XYZ avalia diferentes graus e políticas baseados em critérios relacionados com as características da demanda (GARCIA, 2010). Besta et al. (2015) corroboram, ao afirmarem que diferentes políticas podem ser adotadas para itens que tem consumo mais regular, sendo que os produtos se classificam da seguinte forma: $X$ - indica os itens com maior regularidade de demanda, sem grandes flutuações no consumo; $Y$ - reúne os itens que demonstram alguma oscilação de demanda; e Z representa os materiais com consumo mais irregular e com previsibilidade mais limitada.

Já a curva $A B C$, Letti et al. (2014) salientam que é um método simples e prático na solução de problemas de gestão dos estoques, seja pela forma como ela traz os resultados com base nos números coletados nas empresas ou por permitir a elaboração de graus de importância para os produtos estocados. Em estudos semelhantes, Lélis (2012) destaca que a classificação da curva ABC é uma importante ferramenta de gestão, pois possibilita distinguir os itens mais significativos do estoque. Para a autora, os itens de classe 
A representam $20 \%$ dos produtos e equivalem a $80 \%$ do valor monetário, os itens de classe B representam $30 \%$ dos produtos e equivalem a $15 \%$ do valor e os itens de classe C representam $50 \%$ dos produtos e equivalem a $5 \%$ do valor monetário.

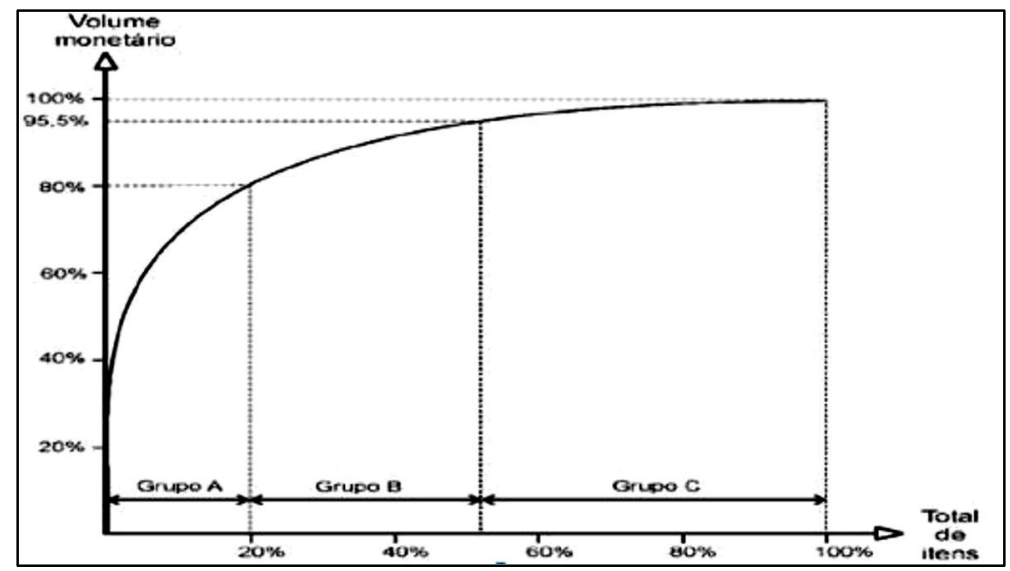

Figura 1: Curva de abc para itens em estoque. Fonte: adaptado de Peinado et al. (2007).

Os resultados foram analisados à luz de uma metodologia de estudo de caso com aplicação de revisão bibliográfica, análise de documentos e observação participante, o que fortaleceu a interpretação favorável acerca da problemática deste trabalho. A escolha do tema justifica-se ao perceber a relevância adquirida pela gestão dos estoques no ambiente organizacional na contemporaneidade, uma vez que conhecer as particularidades do estoque, reproduz a qualidade do fluxo de bens e serviços da empresa, tornando-se em fator-chave do conjunto de valores logísticos oferecidos aos clientes (BALLOU, 2014). Este evento é defendido por Nogueira (2012) ao versar que:

A decisão de estocar ou não um determinado produto dependerá muito de sua particularidade quanto a sua complexidade ou facilidade de aquisição. O dimensionamento de um estoque de forma adequada e o conhecimento das particularidades dos produtos, por parte da equipe responsável pelo ressuprimento, é um fator de grande importância para a qualidade no nível de serviço no atendimento ao cliente, seja ele interno ou externo.

Por fim, interpretou-se os resultados no saber da classificação de criticidade XYZ a partir dos dados obtidos pela Curva $A B C$, o qual a gestão de estoque glosa especificamente em preocupar-se com modernas técnicas de gerenciamento dos estoques, pois quando bem empregadas, impactam de maneira substancial em toda a empresa (BALLOU, 2014).

\section{METODOLOGIA}

O trabalho consiste em uma pesquisa descritiva analítica, o que segundo Leite (2012) é utilizada para descrever e interpretar fenômenos, observando-os em sua natureza e em seus processos. Para este trabalho foi utilizado o estudo de caso, que de acordo com Gil (2010), o objetivo é a análise profunda e exaustiva de uma ou poucas questões, permitindo o conhecimento amplo e detalhado.

O estudo de caso é a estratégia escolhida para a análise de acontecimentos contemporâneos. A principal característica que o difere de estudos históricos é que a pesquisa histórica é um trabalho mais bibliográfico e documental e o estudo de caso pode utilizar grande variedade de evidências como documentos, artefatos, entrevistas e observações, além de poder valer-se também do estudo histórico 
convencional (YIN, 2001).

Inicialmente, foi realizada uma pesquisa bibliográfica que consistiu em um levantamento de referências teóricas já analisadas e publicadas, o que para Leite (2012) é uma pesquisa realizada a partir de obras já publicadas como livros, jornais, revistas, artigos e dissertações a fim de que se faça uma análise profunda das informações coletadas.

Foi também utilizada a observação participante, o que segundo Richardson (citado por LEITE, 2012) “o observador não é apenas um espectador do fato que está sendo estudado, ele se coloca na posição e ao nível dos outros elementos humanos que compõem o fenômeno a ser observado". Por fim, empregou-se a análise de documentos, o que segundo Leite (2012) é utilizada para colher fatos e informações importantes na descrição dos fatos ocorridos. Para a análise e coleta dos dados foi utilizado o relatório de faturamento por grupo do ano de 2018.

Durante a coleta de dados para o construto da curva $A B C$, amostras não probabilísticas foram empregadas, o que segundo Vergara (2010), não é baseada em métodos matemáticos, dependendo exclusivamente de critérios do pesquisador. Segundo Gonçalves (2009), são utilizadas em pesquisa quando há uma restrição de cunho operacional ao uso da amostragem probabilística, como, por exemplo, o fato de a população ser infinita ou de não se ter acesso a todos os elementos da mesma. Deste modo, segundo Costa Neto (1977), amostras não probabilísticas são muitas vezes empregadas em trabalhos acadêmicos pela sua simplicidade. Ainda segundo Levine et al. (2008) amostras não probabilísticas podem oferecer vantagens, tais como conveniência, velocidade e baixo custo.

A empresa estudada está situada na Zona da Mata em MG, atua no ramo do agronegócio e caracteriza-se por apresentar uma estrutura de pequeno a médio porte. Passou recentemente por uma ampliação de sua linha de produção e reestruturação do espaço físico da loja. Com a finalidade de manter o sigilo da instituição, denominaremos a empresa como Ômega. A organização atualmente comercializa produtos agrícolas na cidade de Barbacena, além de possui unidades em outras cidades mineiras, o que demonstra forte atuação no estado de Minas Gerais.

A transferência de produtos entre unidades ocorre pelo modal rodoviário e o processo de armazenagem e estocagem de produtos, são realizados pelos próprios funcionários da empresa, não terceirizando estas duas etapas da cadeia de suprimentos. A empresa possui uma gerência específica de estoques e, a esta gerência, subordinam-se a coordenação de suprimentos, a coordenação de compras e a coordenação de operações logísticas. A coordenação de operações logísticas se subdivide em duas subáreas: armazenagem e expedição e logística rodoviária.

Para a elaboração da classificação $A B C$ (Tabela 1) e do gráfico da curva $A B C$ da empresa Ômega (Gráfico 1), foram utilizados 30 grupos de produtos do faturamento de 2018 , classificados para o eixo das ordenadas, as classes A (80\%), B (15\%) e C (5\%), conforme limites apresentados por Lélis (2012).

Para classificação $\mathrm{XYZ}$, como não há na literatura um parâmetro para aferir a criticidade, foram elaborados em conjunto com setor de depósito, área de gerenciamento e administrativo da loja, dez critérios (Tabela 2) a fim de se definir a criticidade dos mesmos 30 grupos de produtos pesquisados para a elaboração 
da Curva $A B C$ - para isso, os denominados 'requisitos de criticidade' foram pontuados de zero a dez, sendo a nota zero (mínima criticidade) e dez (máxima criticidade), sendo que o somatório dos pontos de cada requisito define o nível de criticidade do grupo analisado. Para o grupo cujo somatório total foi acima de 60 pontos, a classificação de criticidade foi Z, pontuação entre 59 e 31 pontos, o nível de criticidade foi Y e igual ou abaixo de 30 pontos, isto é, com baixa criticidade, o nível foi $X$.

\section{RESULTADOS E DISCUSSÃO}

Ballou (2014) defende que a distribuição física é toda movimentação de produto, que vai desde a produção e estocagem até a entrega do produto, e, após análise dos documentos, percebeu-se que as rotinas da distribuição física da empresa converge com o pensamento do autor, no entanto, foi observado em planilhas que a margem de lucratividade da empresa é calculada com base nos custos, e existem casos onde o cliente recolhe a mercadoria na própria loja, o que diminui consideravelmente o custo com as entregas de mercadoria. Dessa forma, a preocupação percebida é que a empresa busca alternativas de evitar que a mercadoria fique ociosa e se transforme em obsoleta no estoque.

Foi observado também que alguns produtos são sazonais, como por exemplos determinados tipos de adubos que são utilizados somente no período de plantio ou pós-plantio (período de julho a novembro) isto também acontece com outros tipos de produtos, o que leva uma análise mais aprofundada e individual em cada grupo; essa particularidade, independente em qual grupo seja, influencia diretamente na disponibilidade dos produtos nas gôndolas do depósito, o que também impacta diretamente nos pedidos de compra (BALLOU, 2014).

Para aumentar a eficiência da entrega dos produtos sazonais, a empresa realiza sua disposição próxima a área de carregamento do depósito, uma vez que isso permite a fluidez de saída da mercadoria, a resultar em um processo logístico mais eficiente e colaboradores menos desgastados física e psicologicamente (já que os processos são facilitados). Na visão de Sucena (2012), deve-se intensificar a cooperação entre os participantes do canal, além de garantir sua rápida disponibilidade de produtos nos locais certos e no momento certo.

Em última análise, percebemos que a disposição física dos produtos é muito importante para que todo o processo tenha sucesso, uma vez que não adianta efetuar grandes volumes de vendas no campo, sem produto disponível para entrega, ou até mesmo uma demora no processo de entrega. Nesse aspecto, foi detectado através de análises nos documentos da empresa, que pedidos de vendas foram cancelados devido à demora no processamento das entregas. Ainda, segundo Sucena (2012), as atividades de distribuição física dos produtos no depósito, iniciam previamente, desde o pedido de compra do fornecedor, transporte, armazenagem, processamento das vendas e entrega.

Quanto à classificação de criticidade $X Y Z$, a partir dos dados da curva $A B C$ coletados, foi identificado que o sistema da empresa permite gerar relatórios por período, o que é um facilitador para um maior entendimento dos períodos de sazonalidade para determinadas mercadorias. Lopes et al., (2008) corrobora com tal afirmativa, ao destacarem a importância de controles que possibilitem aos gestores a visualização de 
itens que necessitam de mais atenção no estoque.

Abaixo, apresenta-se a elaboração da classificação ABC (Tabela 1) sendo utilizados 30 grupos de produtos do faturamento de 2018. Logo em seguida, apresenta-se o Gráfico 1 com a representação da curva $A B C$ na empresa pesquisada.

Tabela 1: Classificação abc por grupo de produtos - faturamento 2018.

\begin{tabular}{|c|c|c|c|c|c|c|c|c|c|c|}
\hline $\mathbf{N}^{\circ}$ & $\begin{array}{l}\text { Grupo de } \\
\text { Produtos }\end{array}$ & Quantidade & Valor & $\begin{array}{c}\text { Represent. no } \\
\text { faturamento total }\end{array}$ & $\begin{array}{l}\text { Percentual } \\
\text { acumulado }\end{array}$ & Classificação & Classe & Corte & $\begin{array}{c}\text { Proporção de } \\
\text { produtos }\end{array}$ & $\begin{array}{c}\text { Proporção } \\
\text { de valor }\end{array}$ \\
\hline 1 & Grupo 1 & 298374 & $\mathrm{R} \$ 983.642,25$ & $53,43 \%$ & $53,43 \%$ & A & $A=2$ & $80,00 \%$ & $3,45 \%$ & 0,50 \\
\hline 2 & Grupo 2 & 33657 & $\mathrm{R} \$ 453.267,00$ & $24,62 \%$ & $78,04 \%$ & A & $B=3$ & $95,00 \%$ & $17,24 \%$ & 4,51 \\
\hline 3 & Grupo 3 & 2254 & $\mathrm{R} \$ 185.397,86$ & $10,07 \%$ & $88,11 \%$ & $\mathrm{~B}$ & $C=30$ & $100,00 \%$ & $79,31 \%$ & 22,86 \\
\hline 4 & Grupo 4 & 1254 & $\mathrm{R} \$ 52.090,24$ & $2,83 \%$ & $90,94 \%$ & $\mathrm{~B}$ & & & & \\
\hline 5 & Grupo 5 & 2143 & $\mathrm{R} \$ 46.178,65$ & $2,51 \%$ & $93,45 \%$ & $B$ & & & & \\
\hline 6 & Grupo 6 & 4325 & $\mathrm{R} \$ 36.765,98$ & $2,00 \%$ & $95,45 \%$ & C & & & & \\
\hline 7 & Grupo 7 & 2376 & $\mathrm{R} \$ 19.991,85$ & $1,09 \%$ & $96,53 \%$ & $C$ & & & & \\
\hline 8 & Grupo 8 & 2009 & $\mathrm{R} \$ 18.654,58$ & $1,01 \%$ & $97,55 \%$ & $C$ & & & & \\
\hline 9 & Grupo 9 & 547 & $\mathrm{R} \$ 15.337,99$ & $0,83 \%$ & $98,38 \%$ & $\mathrm{C}$ & & & & \\
\hline 10 & Grupo 10 & 877 & $\mathrm{R} \$ 10.400,66$ & $0,56 \%$ & $98,94 \%$ & C & & & & \\
\hline 11 & Grupo 11 & 76 & $R \$ 5.317,58$ & $0,29 \%$ & $99,23 \%$ & C & & & & \\
\hline 12 & Grupo 12 & 879 & $\mathrm{R} \$ 2.829,42$ & $0,15 \%$ & $99,39 \%$ & $\mathrm{C}$ & & & & \\
\hline 13 & Grupo 13 & 48 & $\mathrm{R} \$ 1.853,96$ & $0,10 \%$ & $99,49 \%$ & $C$ & & & & \\
\hline 14 & Grupo 14 & 67 & $\mathrm{R} \$ 1.742,45$ & $0,09 \%$ & $99,58 \%$ & C & & & & \\
\hline 15 & Grupo 15 & 2435 & $\mathrm{R} \$ 1.306,90$ & $0,07 \%$ & $99,65 \%$ & $\mathrm{C}$ & & & & \\
\hline 16 & Grupo 16 & 818 & $\mathrm{R} \$ 1.194,26$ & $0,06 \%$ & $99,72 \%$ & $C$ & & & & \\
\hline 17 & Grupo 17 & 465 & $\mathrm{R} \$ 1.181,44$ & $0,06 \%$ & $99,78 \%$ & C & & & & \\
\hline 18 & Grupo 18 & 254 & $\mathrm{R} \$ 1.143,31$ & $0,06 \%$ & $99,84 \%$ & $C$ & & & & \\
\hline 19 & Grupo 19 & 45 & $\mathrm{R} \$ 977,97$ & $0,05 \%$ & $99,90 \%$ & C & & & & \\
\hline 20 & Grupo 20 & 99 & $\mathrm{R} \$ 710,63$ & $0,04 \%$ & $99,94 \%$ & C & & & & \\
\hline 21 & Grupo 21 & 354 & $\mathrm{R} \$ 593,00$ & $0,03 \%$ & $99,97 \%$ & C & & & & \\
\hline 22 & Grupo 22 & 98 & $\mathrm{R} \$ 129,14$ & $0,01 \%$ & $99,98 \%$ & $C$ & & & & \\
\hline 23 & Grupo 23 & 564 & $\mathrm{R} \$ 121,99$ & $0,01 \%$ & $99,98 \%$ & $C$ & & & & \\
\hline 24 & Grupo 24 & 85 & $\mathrm{R} \$ 91,45$ & $0,00 \%$ & $99,99 \%$ & C & & & & \\
\hline 25 & Grupo 25 & 89 & $\mathrm{R} \$ 79,02$ & $0,00 \%$ & $99,99 \%$ & $C$ & & & & \\
\hline 26 & Grupo 26 & 10 & $\mathrm{R} \$ 74,47$ & $0,00 \%$ & $100,00 \%$ & C & & & & \\
\hline 27 & Grupo 27 & 4 & $\mathrm{R} \$ 25,35$ & $0,00 \%$ & $100,00 \%$ & C & & & & \\
\hline 28 & Grupo 28 & 9 & $\mathrm{R} \$ 24,50$ & $0,00 \%$ & $100,00 \%$ & $C$ & & & & \\
\hline 29 & Grupo 29 & 1 & $\mathrm{R} \$ 22,67$ & $0,00 \%$ & $100,00 \%$ & C & & & & \\
\hline 30 & Grupo 30 & 2 & $\mathrm{R} \$ 15,00$ & $0,00 \%$ & $100,00 \%$ & C & & & & \\
\hline TOTAL & $\mathrm{R} \$ 1.841 .161,53$ & $100,00 \%$ & $100,00 \%$ & & & & & & & \\
\hline
\end{tabular}

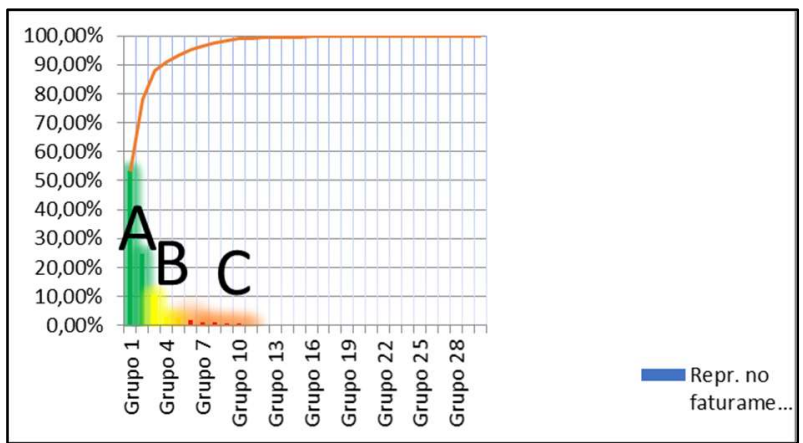

Gráfico 1: Representação gráfica da curva ABC por grupo - Faturamento 2018.

A partir da elaboração da curva $A B C$, foi realizado a interpretação dos dados para a construção da classificação da criticidade XYZ por grupo de produtos, como descrito na visão de Babai et al. (2015), ao afirmarem que a classificação poderá auxiliar a gestão ao criar mais um critério técnico de dados para análise da empresa, conforme demonstrado na Tabela 2:

Analisando o ponto de vista de Babai et al. (2015) para melhor atender à necessidade dos clientes que a cada dia estão mais exigentes, a classificação XYZ melhorou a disposição dos produtos na empresa estudada. Esta visão se aplica à disposição dos produtos no depósito, onde aperfeiçoou o trabalho dos estoquistas. 
Tabela 2: Classificação XYZ por grupo de produtos - faturamento 2018.

\begin{tabular}{|c|c|c|c|c|c|c|c|c|c|c|c|c|c|}
\hline$\stackrel{N}{N}$ & $\begin{array}{l}\text { Grupo de } \\
\text { Produto }\end{array}$ & $\begin{array}{c}\text { Falta de } \\
\text { mercador } \\
\text { ia no } \\
\text { fornecedo } \\
r \\
\end{array}$ & $\begin{array}{l}\text { Prazo de } \\
\text { Recebimen } \\
\text { to }\end{array}$ & $\begin{array}{l}\text { Fornecimen } \\
\text { to exclusivo }\end{array}$ & $\begin{array}{l}\text { Sujeito à } \\
\text { sazonalida } \\
\text { de }\end{array}$ & $\begin{array}{l}\text { Vencimen } \\
\text { to no } \\
\text { estoque }\end{array}$ & $\begin{array}{l}\text { Rodízi } \\
\text { o de } \\
\text { cultur } \\
\text { a }\end{array}$ & $\begin{array}{l}\text { Previsã } \\
\text { o de } \\
\text { vendas }\end{array}$ & $\begin{array}{c}\text { Demand } \\
\text { a }\end{array}$ & $\begin{array}{c}\text { Risco } \\
\text { pré- } \\
\text { vend } \\
\text { a }\end{array}$ & $\begin{array}{c}\text { Custo } \\
\text { de } \\
\text { Arma } \\
\text { z. }\end{array}$ & $\begin{array}{c}\text { Acumulad } \\
0\end{array}$ & $\begin{array}{c}\text { Classificaçã } \\
0\end{array}$ \\
\hline 1 & Grupo 1 & 10 & 10 & 10 & 8 & 10 & 3 & 10 & 10 & 7 & 8 & 86 & $z$ \\
\hline 2 & Grupo 2 & 10 & 0 & 0 & 6 & 0 & 0 & 10 & 10 & 0 & 10 & 46 & $\mathrm{y}$ \\
\hline 3 & Grupo 3 & 8 & 5 & 6 & 10 & 10 & 0 & 10 & 10 & 0 & 7 & 66 & $z$ \\
\hline 4 & Grupo 4 & 5 & 10 & 7 & 0 & 10 & 5 & 7 & 10 & 5 & 4 & 63 & $z$ \\
\hline 5 & Grupo 5 & 3 & 6 & 10 & 9 & 8 & 5 & 8 & 5 & 7 & 8 & 69 & $z$ \\
\hline 6 & Grupo 6 & 10 & 10 & 10 & 10 & 10 & 0 & 9 & 10 & 10 & 6 & 85 & $z$ \\
\hline 7 & Grupo 7 & 8 & 4 & 9 & 0 & 6 & 10 & 10 & 9 & 10 & 8 & 74 & $z$ \\
\hline 8 & Grupo 8 & 10 & 10 & 8 & 3 & 0 & 0 & 7 & 10 & 8 & 10 & 66 & $z$ \\
\hline 9 & Grupo 9 & 10 & 10 & 10 & 8 & 10 & 10 & 10 & 10 & 10 & 8 & 96 & $z$ \\
\hline $\begin{array}{l}1 \\
0 \\
\end{array}$ & Grupo 10 & 5 & 6 & 9 & 4 & 10 & 10 & 10 & 10 & 10 & 5 & 79 & $z$ \\
\hline $\begin{array}{l}1 \\
1 \\
\end{array}$ & Grupo 11 & 4 & 8 & 5 & 3 & 0 & 5 & 9 & 9 & 7 & 10 & 60 & z \\
\hline $\begin{array}{l}1 \\
2 \\
\end{array}$ & Grupo 12 & 10 & 0 & 2 & 10 & 4 & 0 & 5 & 9 & 2 & 1 & 43 & $y$ \\
\hline $\begin{array}{l}1 \\
3 \\
\end{array}$ & Grupo 13 & 0 & 3 & 4 & 5 & 3 & 6 & 2 & 5 & 8 & 5 & 41 & $y$ \\
\hline $\begin{array}{l}1 \\
4 \\
\end{array}$ & Grupo 14 & 2 & 5 & 7 & 3 & 2 & 0 & 0 & 1 & 4 & 3 & 27 & $x$ \\
\hline $\begin{array}{l}1 \\
5 \\
\end{array}$ & Grupo 15 & 1 & 0 & 1 & 0 & 0 & 0 & 2 & 1 & 1 & 8 & 14 & $x$ \\
\hline $\begin{array}{l}1 \\
6 \\
\end{array}$ & Grupo 16 & 0 & 1 & 3 & 1 & 0 & 0 & 1 & 3 & 1 & 1 & 11 & $x$ \\
\hline $\begin{array}{l}1 \\
7 \\
\end{array}$ & Grupo 17 & 3 & 7 & 10 & 8 & 10 & 10 & 10 & 9 & 10 & 9 & 86 & $z$ \\
\hline $\begin{array}{l}1 \\
8\end{array}$ & Grupo 18 & 0 & 3 & 5 & 5 & 0 & 0 & 7 & 4 & 0 & 1 & 25 & $x$ \\
\hline $\begin{array}{l}1 \\
9 \\
\end{array}$ & Grupo 19 & 5 & 3 & 7 & 10 & 7 & 6 & 3 & 5 & 8 & 1 & 55 & y \\
\hline $\begin{array}{l}2 \\
0 \\
\end{array}$ & Grupo 20 & 10 & 8 & 10 & 10 & 9 & 10 & 10 & 10 & 10 & 8 & 95 & $z$ \\
\hline $\begin{array}{l}2 \\
1 \\
\end{array}$ & Grupo 21 & 6 & 8 & 10 & 10 & 8 & 0 & 8 & 7 & 9 & 10 & 76 & $z$ \\
\hline $\begin{array}{l}2 \\
2 \\
\end{array}$ & Grupo 22 & 0 & 0 & 3 & 0 & 0 & 0 & 1 & 3 & 0 & 4 & 11 & $x$ \\
\hline $\begin{array}{l}2 \\
3 \\
\end{array}$ & Grupo 23 & 10 & 9 & 10 & 10 & 7 & 0 & 9 & 9 & 9 & 8 & 81 & $z$ \\
\hline $\begin{array}{l}2 \\
4 \\
\end{array}$ & Grupo 24 & 2 & 0 & 3 & 0 & 0 & 0 & 2 & 1 & 2 & 1 & 11 & $x$ \\
\hline $\begin{array}{l}2 \\
5 \\
\end{array}$ & Grupo 25 & 0 & 0 & 1 & 0 & 0 & 0 & 0 & 1 & 0 & 1 & 3 & $x$ \\
\hline $\begin{array}{l}2 \\
6 \\
\end{array}$ & Grupo 26 & 1 & 1 & 10 & 0 & 0 & 0 & 3 & 1 & 1 & 1 & 18 & $x$ \\
\hline $\begin{array}{l}2 \\
7 \\
\end{array}$ & Grupo 27 & 9 & 3 & 3 & 0 & 0 & 0 & 8 & 1 & 1 & 1 & 26 & $x$ \\
\hline $\begin{array}{l}2 \\
8 \\
\end{array}$ & Grupo 28 & 0 & 0 & 0 & 0 & 0 & 0 & 3 & 1 & 2 & 1 & 7 & $x$ \\
\hline $\begin{array}{l}2 \\
9 \\
\end{array}$ & Grupo 29 & 0 & 0 & 10 & 0 & 0 & 0 & 5 & 1 & 8 & 1 & 25 & $x$ \\
\hline \multirow[t]{5}{*}{$\begin{array}{l}3 \\
0 \\
\end{array}$} & Grupo 30 & 0 & 0 & 7 & 0 & 0 & 0 & 2 & 1 & 0 & 1 & 11 & $\mathrm{x}$ \\
\hline & & & & & & & & & & & Classe & $\begin{array}{c}\text { Parâmetr } \\
\text { o }\end{array}$ & $\begin{array}{c}\text { Quantidad } \\
\text { e de grupos } \\
\text { pertencent } \\
\text { es }\end{array}$ \\
\hline & & & & & & & & & & & $x$ & $<30$ & 12 \\
\hline & & & & & & & & & & & $y$ & $\begin{array}{l}>=31 \\
<=59\end{array}$ & 4 \\
\hline & & & & & & & & & & & $z$ & $>60$ & 14 \\
\hline
\end{tabular}

Com o cruzamento das informações entre os dados da curva $A B C$ e a classificação de criticidade XYZ (Tabela 3) foi realizada uma subdivisão em cores para facilitar o acompanhamento: em amarelo estão representados os grupos de alto valor agregado, a considerar a representatividade no faturamento e de alto grau de criticidade (grupos com grau de atenção elevado); em verde estão os grupos medianos, onde são indispensáveis, pois, geram faturamento para empresa, contudo com grau de criticidade de fácil solução, e já a classificação em azul enquadra os grupos de baixa criticidade e baixa representatividade no faturamento. 
Tabela 3: Combinação da classificação abc e xyz - 2018 (grupos da empresa pesquisada).

\begin{tabular}{|l|l|l|l|}
\hline & A & B & C \\
\hline$X$ & - & - & $14,15,16,18,22,24,25,26,27,28,29,30$ \\
\hline$Y$ & 2 & - & $12,13,19$ \\
\hline$Z$ & 1 & $3,4,5$ & $6,7,8,9,10,11,17,20,21,23$ \\
\hline
\end{tabular}

Neste contexto de cruzamento de dados, podemos perceber que para a empresa pesquisada, o grupo que possui maior representatividade em seu faturamento também é o grupo com maior criticidade, uma vez que nas análises, foi constatado que é nesses grupos de produtos que a empresa concentra seus maiores controles dos pedidos, devido ao seu faturamento. A atenção acontece desde a prospecção da venda, onde é identificada a necessidade de compra, passando ao fornecedor que detém a atenção devido à disponibilidade no fornecimento e tempo de entrega, aos cuidados no interior do depósito da loja (vencimento, disposição, excesso de produto, e cuidados na armazenagem), entre outras políticas e cuidados tomados em todos os setores, para que tudo flua como desejado (BESTA et al., 2015).

Outro aspecto que chamou atenção foi a quantidade de grupos classificados como $C X$, uma vez que são grupos de baixo faturamento e baixa criticidade. Nesta análise, foi observou-se uma grande preocupação da empresa pesquisada, pois, foi constatado que para esses grupos são empregados investimentos e que talvez pudessem estar sendo mais bem direcionados para grupos que possuem maior representatividade, isto é, os que representam maior rotatividade no estoque. Nesta análise, foi possível chamar a atenção para a importância de se utilizar outros critérios para gerenciamento de estoque.

Contudo, Ballou (2014) defende que para a gestão poder tomar a melhor decisão, é necessário obter conhecimento de todos os produtos e demandas de vendas, e é para isso que servem as análises, pois, assim é possível verificar a troca do mix de produtos, atendendo melhor o gerenciamento dos estoques da empresa.

\section{CONCLUSÕES}

Por fim, este tipo de trabalho favorece uma compreensão ampla da necessidade em interpretar aspectos relacionados à gestão de estoques, que lhe convém (aqui uma empresa mineira do agronegócio), estudar suas peculiaridades, assim como instigar o acadêmico em Administração acerca da necessidade de pensamento econômico e de estratégias na gestão de ativos, condizentes com a realidade mercadológica do setor ao qual pertence.

A empresa em estudo constatou que após a aplicação da curva $A B C$ juntamente com o cruzamento de informações da classificação de criticidade $X Y Z$, seus custos de estocagem e tempo de execução das tarefas do setor de depósito diminuíram devido a melhor localização dos produtos de acordo com a sua sazonalidade, além de diminuir o esforço dos colaboradores que ali trabalham, outrossim contribuiu também para análise de reposição de estoque, a evitar faltas ou excessos de mercadoria por parte do gestor que efetua as compras para movimentar seu mercado.

Apesar da empresa precisar se aprofundar nos conhecimentos em classificação $\mathrm{XYZ}$, foi possível aplicar e classificar os grupos pelos índices de criticidade definidos, o que nunca foi analisado pelo gerente 
de vendas, já que para ele, até o momento, se preocupava somente com o valor faturado e com os produtos de maior rotatividade no estoque. Com a demonstração do estudo $\mathrm{XYZ}$, foi possível alertá-lo sobre a importância em utilizar outros critérios para gerenciamento de estoque, o que contribuiu para explorar outros meios para melhorar seu mix de produto e evitar perdas com produtos ociosos ou obsoletos.

Em síntese, executar atividades com estes fins, oportuniza o saber científico e em uma visão micro, fortalece a condição de futuro Administrador, o qual deve planejar e alcançar metas definidas e gerenciar corretamente os ativos que the são confiados, assim como propor melhorias na gestão de estoques da empresa a qual pertence, neste caso, uma empresa mineira de pequeno a médio pertencente ao agronegócio Brasileiro.

\section{REFERÊNCIAS}

BABAI, M. Z.; LADHARI, T.; LAJILI, I.. On the inventory performance of multi-criteria classification methods: empirical investigation. International Journal of Production Research, v.53, n.1, p.279-290, 2015.

BALLOU, R. H.. Logística empresarial: Transportes, administração de materiais e distribuição física. São Paulo: Atlas, 2014.

BESTA, P.; JANOVSKÁ, K.; BUMBOVÁ, M.. The possibilities of the structure and variability evaluation of inventory consumption. International Scientific Journal about Logistics, v.2, n.3, p.21-25, 2015. DOI: http://doi.org/doi:10.22306/al.v2i3.44

BOWERSOX, D.; CLOSS, D.. Logística empresarial: o processo de integração da cadeia de suprimentos. São Paulo: Atlas, 2001.

COSTA NETO, P. L. O.. Estatística. São Paulo: Edgard Blücher, 1977.

GARCIA, E. S.. Proposta de um modelo de gerenciamento de categoria de bebida à base de soja no Angeloni da av. Centenário na cidade de Criciúma. Monografia (Especialização em Gestão Empresarial) - Universidade do Extremo Sul Catarinense, Criciúma, 2010.

GIL, A. C.. Como elaborar projetos de pesquisa. 5 ed. São Paulo: Atlas, 2010.

GONÇALVES, J. B.. Amostragem: conceitos básicos. EBA, 2009.

LEITE, F. T.. Metodologia científica: métodos e técnicas de pesquisa (monografias, dissertações, teses e livros). 3 ed. Aparecida: Ideias e Letras, 2012.
LÉLIS, E. C.. Administração da Produção. São Paulo: Pearson Education do Brazil, 2012.

LETTI, G. C.; GOMES L. C.. Curva ABC: Melhorando o gerenciamento de estoques de produtos acabados para pequenas empresas distribuidoras de alimentos. Update, Porto Alegre, v.1, n.2, p.66-86, 2014

LEVINE, D. M.; STEPHAN, D. F.; SZABAT, K. A.. Estatística: teoria e aplicações. 5 ed. Rio de Janeiro: TLC, 2008.

LOPES, R. A.; LIMA, J. F. G.. Planejamento e controle da produção: um estudo de caso no setor de artigos esportivos de uma indústria manufatureira. In: ENCONTRO NACIONAL DE ENGENHARIA DE PRODUÇÃO: A INTEGRAÇÃO DE CADEIAS PRODUTIVAS COM A ABORDAGEM DA MANUFATURA SUSTENTÁVEL, 28. Anais. Rio de Janeiro: ENEGEP, 2008

NOGUEIRA, A. S.. Logística Empresarial. Uma visão local com pensamento globalizado. 3 ed. São Paulo: Atlas, 2012.

PEINADO, J.; GRAEML, A. R.. Administração da produção: operações industriais de serviços. Curitiba: UnicenP, 2007.

POZO, H.. Administração de recursos materiais e patrimoniais: uma abordagem logística. 4 ed. São Paulo: Atlas, 2007

SUCENA, M.. Engenharia de Produção: Logística e Distribuição. Rio de Janeiro: UNESA, 2012.

VERGARA, S. C.. Projetos e relatórios de pesquisa em administração. 12 ed. São Paulo: Atlas, 2010.

YIN, R. K.. Estudo de Caso: Planejamento e métodos. 2 ed. São Paulo: Bookman, 2001.

A CBPC - Companhia Brasileira de Produção Científica (CNPJ: 11.221.422/0001-03) detém os direitos materiais desta publicação. Os direitos referem-se à publicação do trabalho em qualquer parte do mundo, incluindo os direitos às renovaç̃ões, expansões e disseminações da contribuiç̃o, bem como outros direitos subsidiários. Todos os trabalhos publicados eletronicamente poderão posteriormente ser publicados em coletâneas impressas sob coordenação da Sustenere Publishing, da Companhia Brasileira de Produção Científica e seus parceiros autorizados. Os (as) autores (as) preservam os direitos autorais, mas não têm permissão para a publicação da contribuição em outro meio, impresso ou digital, em português ou em tradução. 